\title{
Professional regulation of nutritionists: where are we now?
}

\author{
Jacqueline P. Landman ${ }^{1 *}$ and Stephen A. Wootton ${ }^{2}$ \\ ${ }^{1}$ The Nutrition Society, Cambridge Court, London W67NJ, UK \\ ${ }^{2}$ Institute of Human Nutrition, University of Southampton, Southampton SO16 7PX, UK
}

\begin{abstract}
Waterlow's (1981) Sixth Boyd Orr Lecture on a 'crisis of identity for nutrition' stimulated the Nutrition Society's drive to professionalisation. Twenty-five years on, the Society begins a new stage; first, towards an independent voluntary regulator, and then towards statutory regulation. It is timely to reflect on progress and identify the remaining challenges. The Society has made impressive progress as a voluntary regulator since 1991 when the Insitute of Biology opened a register in cooperation with the Institute of Food Science and Technology and the Nutrition Society; the present register is $2 \cdot 75$-fold larger. The Society has specialist standards for course accreditation that enable graduates to apply for direct entry to the register, having met standards of competency in nutrition or public health nutrition. A code of ethics and a statement of professional conduct underpin a functioning system for oversight and governance that protects the public, the hallmark of all professions. Registered nutritionists lay easy claim to a unique science basis for their profession. A scheme for continuing professional development (CPD) started in July 2006, 1 year before a sample audit starts to show the link between CPD and re-registration. The scheme will be piloted in the first year. The critical challenge is the issue of identity. Waterlow (1981) stated that professional registration must lead explicitly and formally to a specific vocation, an occupation that provides services that society requires and one that contributes to the well-being and health of all. The present time may be the last and best chance for nutritionists, as nutrition has a higher priority for government in the UK than ever before. The Society has begun to help in strategic public health workforce planning and development; new and still plastic, it is the ideal locus from which a discipline and a profession can emerge. The CPD scheme will work if it helps nutritionists meet their own needs; more mutual cooperation and consensus about real world standards of performance are needed. Nutritionists need to show how they actually contribute to national health and/or wealth. Then, sustained resources can be advocated for and the support of the voting public and legislators secured, without which it will not be possible to get the legal protection that is desirable for the profession.
\end{abstract}

\section{Nutrition profession: Professionalisation: Occupation: UK}

The present paper is based on an interactive presentation with two objectives. The first objective is to chart progress in professionalisation in nutrition, by analysing the extent to which being a 'nutritionist' means being a member of a modern profession, which in large part is understood to mean a professional that could be regulated by law. The paper identifies the challenges that remain and considers how these challenges are being or may be met. The second objective is to signal formally and openly the beginning of a debate within the Nutrition Society and the nutrition profession that began at the Society's annual summer conference in Aberdeen in July 2006. Alongside internal discussions, the Society will continue to work with partners and stakeholders who share its vision and goals in professionalisation.

It is timely to reflect on progress in professionalisation in nutrition for internal and external reasons. First, there is the internal dynamic of change within the Nutrition Society in the next 2 years, as set out in the final draft of the Strategic Plan 2007-2010 (Nutrition Society, 2006d) agreed at the 2006 Annual General Meeting of the Society. By 2008 the Society will transfer its voluntary register to a new UK Voluntary Register of Nutritionists so that voluntary registration as a nutritionist becomes independent of membership of the learned society. The Society also intends to establish a professional body, an 
Association for Nutritionists that will provide more professional services and support than the Society can provide at present. This structural change will further a goal to attain statutory regulation for the profession of 'nutritionist' by 2010 . These highly significant structural and functional changes are in keeping with most established professions in the UK. For example, doctors are regulated by law through the General Medical Council, whereas the British Medical Association is both trade union and professional association. Dietitians are regulated by law by the Health Professions Council and have The British Dietetics Association as a membership professional body that promotes and protects professional interests, also being a trade union for dietitians.

Professionalisation more than any aspect of the concerns of the Nutrition Society is context-sensitive and contextspecific; public and social policy and public perception shape expections of professionalism as much as the selfdefinitions of professionals, as the Society is already well aware (Landman et al. 1998). Further professionalisation, more than any aspect of the way the Society currently operates, requires full engagement with the wider public as well as becoming more outward looking, as the Society strives to be. For example, the repercussions of globalisation in labour and services may be less pertinent to professionalisation than to the learned society. External drivers have become more important for the professional occupation of, and thus professionalisation in, nutrition in the 21 st century than at any time in the past 25 years. Post devolution there is diversity in England, Northern Ireland, Scotland and Wales in the delivery of nutrition and health policy, programmes, services and care, as well as in education, although not (yet) in professional regulation. Two recent reports (Department of Health, 2006a,b) highlight the need for, and the issues surrounding, the regulation of non-medical health professionals. These reports reflect the need to ensure that the risk of lapses in professionalism can be minimised to protect the public and raise the bar by expecting professionals to demonstrably improve services for the public good. These two reports represent important statements of political expectations and of the technical aspects of professionalism, underpinned by good governance.

The profile of nutrition has risen unprecedentedly in the UK over the past 25 years. Nutrition is integral to both public and social policy in the wake of concerns about obesity, food safety and the scandal of persistent undernutrition (Department of Health, 2004a, 2005a,b,c,d; Food Standards Agency, Wales, 2004; Scottish Executive, 2004). The Food Standards Agency is now the largest public sector employer of nutritionists in the UK and operates at dual levels, within devolved countries and at national level. In the UK as a whole, and in England in particular, government policy seeks to reduce health inequalities and improve health and well-being. This policy shift has led to the need for, and emergence of, new types of public health nutrition practice, supported by short-term funding (The British Dietetic Association and The Nutrition Society, 2002). A shortage of dietitians among allied and other health professionals has created more opportunities for nutritionists as the National Health
Service has expanded (Department of Health, 2000, 2005e). As a result the joint British Dietetic Association and Nutrition Society professional guidance document (The British Dietetic Association and The Nutrition Society, 2002) was published to encourage the employment of nutritionists in National Health Service departments. New emphasis and impetus towards promotion of health and well-being as opposed to curative treatments are part and parcel of the response to The Report of the Chief Medical Officer's Project to Strengthen the Public Health Function (Department of Health, 2001) and the acceptance of the 'fully engaged' scenario (Wanless, 2004).

Modern 21st century professionals are required to give greater emphasis to the public good and to patient or client centeredness, catering for client choice (Department of Health, 2004b). New and more flexible occupational boundaries are overseen by new voluntary registers in many sectors, e.g. UK Voluntary Register of Public Health Specialists, Register for Exercise Professionals and the Council for the Registration of Forensic Practitioners. New statutory regulators oversee longstanding health professions, e.g. the Health Professions Council and the UK Nursing and Midwifery Council, with a new overarching statutory body in the Council for Healthcare Regulatory Excellence. It is worth noting that regulation has also been extended to social workers and teachers in the UK. In summary, there has been a marked general increase in professionalisation in the wider UK society, of which nutritionists need to take careful note so that the lessons can be learned to their own advantage.

\section{Professional registration in nutrition 1990-2006}

John Waterlow (1981) delivered the Sixth Boyd Orr Memorial Lecture entitled 'A crisis for nutrition', in which he highlighted three inspirational features of Boyd Orr: his ability to bridge intellectual and other gaps; tremendous courage; great concern with the practical. Waterlow (1981) stated that nutritionists had 'no recognised or required qualifications other than those for dietitians', pointing out that in the UK there was "virtually no career structure except in a handful of university departments or research institutes'. He stressed that part of the crisis was that 'there is no relationship between existing demands and real needs' and said that it was 'our job' as a Society to define those needs as a first step towards establishing nutrition as a profession. One of the key questions posed by Waterlow (1981) was 'Is 'nutritionist' a profession for which entry qualifications have been defined and are required.'

The Society responded to Waterlow's challenge by professionalising. Thanks to the drive and commitment over many years of Dr Ann Walker, the Society established a register of Accredited Nutritionists, in partnership with the Institute of Food Science and Technology and held by the Institute of Biology, both chartered bodies, which opened in 1991 (Institute of Biology, 1991). This register was open to members of each partner society and admitted members with 'acceptable' formal degree-level qualifications or their equivalents (Institute of Biology, 1995). Subsequently, in 1997 the Society, under the leadership of 


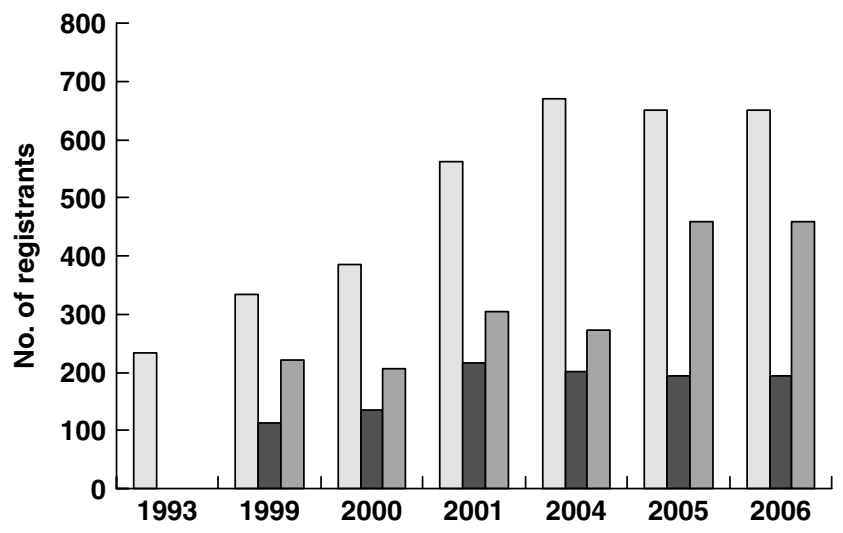

Fig. 1. Growth of the Nutrition Society's Voluntary Nutrition Register, 1993-2006. ( $\square$ ), Total; ( $\square$ ), public health nutrition; ( $\square$ ), nutrition.

Dr Barrie Margetts and Dr Judith Buttriss, developed an independent Nutrition Society register (Nutrition Society, 1997), as documented by Landman et al. (1998). The Society enjoyed the support of the Department of Health, notably through senior officials, Dr Martin Wiseman and Mr Robert Wenlock, and the active participation of the Community Nutrition Group of dietitians. Entry to this new register required evidence of specialist competency in public health nutrition, in addition to competency in nutrition. At that stage the Society explicitly adopted the Department of Health's (1994) Core Curriculum for Nutrition in the Education of Health Professionals as part of its commitment to achieving national policy goals. The professional boundaries between community dietitians and public health nutritionists were defined. In 1999 the Nutrition Society took over the register of Accredited Nutritionists, inviting Accredited Nutritionists to transfer, provided that they became Society members, and offering the new replacement title, Registered Nutritionist with designatory letters RNutr. Transfer to the specialist category Public Health Nutritionist (designatory letters RPHNutr) required evidence of additional specialist competency (Nutrition Society, 1997). At the outset it was stated that there would be one register and one title; no member would hold two titles. The growth of the voluntary register between 1993 and 2006 is shown in Fig. 1.

\section{Retrospective registration criteria: 'grandparenting'}

Professional registration always provides for 'grandparenting', i.e. the admission of nutritionists who can show that they are recognised to be nutritionists even though they have no formal qualifications in nutrition but have learnt nutrition through 7 years (or more) of professional work in, and commitment to, the subject, often at very senior levels (as, for example, described in Ashwell, 1993). In 2002 the target date of 2007 was set for a nutrition degree to become a requirement so that all members of the profession would share a common core of competency in nutrition as befits a modern and maturing profession. A joint Nutrition Society and Association of Professors in Human Nutrition Working Party on Nutrition Science (Nutrition Society, 2003a) set out, and led a wide-ranging

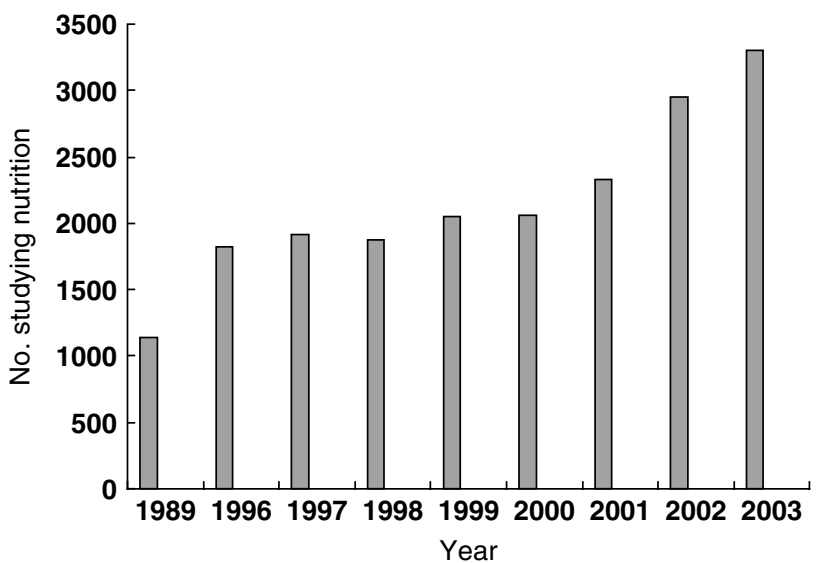

Fig. 2. Trend in numbers of students who gained first degrees in nutrition. Data for universities and polytechnics in 1989 taken from Institute of Biology (1991) and data for universities and university level colleges for 1996-7-2003-4 from the Higher Education Statistical Agency (www.hesa.ac.uk).

consultation to achieve consensus about, the core values and competencies that distinguish an individual eligible for a professional registration and thus a professional career in nutrition. This consensus included and built upon the common core of competencies in the Core Curriculum for Nutrition in the Education of Health Professionals (Department of Health, 1994), also known as the '18 bullet points'. Thus, the Working Party has ensured that all registered nutritionists will share the professional language of nutrition and fundamental nutrition concepts with doctors and nurses who specialise in clinical nutrition (Landman et al. 2006).

\section{Course accreditation and eligibility for direct entry to the register}

In order to support the professional careers of recent graduates the Society established in 2002 the new level of professional registration Associate Nutritionist (designatory letters ANutr) or Associate Public Health Nutritionist (designatory letters APHNutr; Nutrition Society, 2003d). This level of registration was designed to help recent nutrition graduates who held degrees in nutrition, either BSc with single or joint honours or taught postgraduate degrees (but lacked the 3 years of professional experience in nutrition required to be admitted to the register as 'full' registrants) enter professional nutrition careers.

Waterlow (1981) mentioned a 'handful of academic departments' for nutrition. By contrast, in 2003 there were forty-two within the UK responsible for 258 awards at undergraduate level (Nutrition Society, 2003a). Clearly, nutrition is a popular course of study, as the ever-increasing numbers of students applying to or attending university shows (Fig. 2).

Thus, the joint working party of the Nutrition Society and the Association for Professors of Human Nutrition (2003a) proposed that the Society should accredit courses in nutrition, as well as accrediting courses in public health nutrition that first began in 1999 (Nutrition Society, 1997). 
Table 1. Numbers of courses leading to single or joint honours BSc or MSc in Nutrition or Public Health Nutrition accredited by the Nutrition Society, June 2006

\begin{tabular}{lccc}
\hline Professional category & $\begin{array}{c}\text { BSc } \\
\text { degrees }\end{array}$ & $\begin{array}{c}\text { MSc } \\
\text { degrees }\end{array}$ & Total \\
\hline Nutrition (human and animal) & 9 & 3 & 12 \\
Public health nutrition & 7 & 5 & 12 \\
Total & 16 & 8 & 24 \\
\hline
\end{tabular}

Following a pilot study, course accreditation was extended to courses that met the Society's standards of education in nutrition (Nutrition Society, 2005a). By June 2006 twentyfour courses had been accredited (Table 1).

The Society's answer to one of the questions Waterlow (1981) posed is that the qualifications required for entry into the nutrition profession are either a single or joint BSc degree with honours or a taught postgraduate degree, or their equivalent, that demonstrably meet the Society's standards for professional education, This criterion signifies that the accredited universities develop professional competency, ethics and values so that their graduates are eligible to apply for direct entry ('fast track') as associate registrants.

\section{Nutritionist as a professional occupation}

It was anticipated that by signifying that Associate Nutritionists and AssociatePublic Health Nutritionists had met the standards for voluntary professional registration, they would be preferentially employed. To some extent this progression has happened; registration with the Society is a sign of quality for jobs in the National Health Service in nutrition departments (The British Dietetic Association and The Nutrition Society, 2002) and for general practitioners and others in primary care trusts in order to meet National Service Frameworks such as that for CHD (Health Development Agency, 2001). It is often a prerequisite in other public sector posts such as lectureships, in non-departmental governmental organisations and in industry. However, membership of the voluntary register is not yet a universal formal requirement, nor is it imperative for an appointment to any nutrition jobs in any sector.

Professions have defined occupations and, therefore, there is expected to be a career pathway in nutrition that enables a new entrant to chart their career progression within their chosen profession from entry to advancement to the top. A career pathway is an expression of the ways in which needs for nutritionists are translated into demands for their services or expertise. It is important to distinguish a need for nutrition knowledge, nutrition research or even an evidence-base in nutrition for policy from a need for nutrition 'expertise-in-action'. Expertise in action refers to the use of competences in the form of services, care or advice delivered to meet explicit outputs or outcomes that society or employers desire and will pay for, which is a distinction first made by Waterlow (1984). All ancient and, even more so, modern professionalisation entails preparation for defined occupations. The Institute of Biology's
Table 2. Nutritionists professional roles: responses from nutritionists ( $n$ 1535) asked to state up to three activities that occupied most of their time in a survey carried out by Stockley and Associates, independent consultants (Nutrition Society, 2006a)

\begin{tabular}{lrr}
\hline Professional roles & $n$ & $\%$ \\
\hline Community project/programme development & 154 & $8 \cdot 1$ \\
Public Health policy/strategy & 193 & $10 \cdot 0$ \\
Clinical/therapy & 163 & $8 \cdot 4$ \\
Teaching/training/other education & 365 & $18 \cdot 9$ \\
Advice and information & 276 & $14 \cdot 3$ \\
Research & 514 & $26 \cdot 7$ \\
Marketing/media/communication & 91 & $4 \cdot 7$ \\
Product development/regulatory affairs & 87 & $4 \cdot 5$ \\
Other & 79 & $4 \cdot 1$ \\
All roles & 1922 & 100 \\
\hline
\end{tabular}

(1991) review on the training of nutritionists found that graduate career pathways for nutritionists were limited because nutrition graduates reported holding jobs in the private sector ('industry') that were often neither in nutrition nor in science. Health sector graduate work in the UK was confined to nutrition graduates who subsequently studied dietetics.

In order to define what a professional nutritionist is equipped to do (i.e. to answer the question "what is the occupation of a nutritionist') the Society asked the question 'what jobs do nutritionists do'. Published surveys of members of the Nutrition Society that include information about members' occupations and employment preceded the register and so cannot reflect features of registrants (Ashwell \& Cole, 1986; O'Hara-May, 1987). Thus, in 2005 the Society obtained funds from the Department of Health with which it commissioned Stockley and Associates, independent consultants, to undertake research into, among other issues, the occupations of nutritionists. This review formed the basis of the Society's report to the Department of Health, Nutrition Capacity in the UK: Mapping the 'Primary' Nutrition Workforce (Nutrition Society, 2006a). The review revealed that younger registrants held recent $(\leq 5$ years) jobs in the health service, in the practice of public health nutrition, at entry and senior levels. Research and academic jobs dominated but to a lesser extent than among members in the past (Ashwell \& Cole, 1986). Registered Nutritionists were also communicators who worked in the popular and mass media, where they interpret new research, policy and government advice to lay audiences. As there was no clear difference between the roles or employment reported by Registered Nutritionists and Registered Public Health Nutritionists, the overall picture is presented in Table 2.

The lack of databases and formal surveys of voluntary registered nutritionists and other nutrition professionals hampers any assessment of the size and hence capacity of the primary nutrition workforce to which registered nutritionists belong. While the map necessarily provided a provisional picture (Nutrition Society, 2006a), it supported proposals to conceptualise a workforce strategy for the entire nutrition workforce (Landman et al. 2006). Similar problems beset the entire public health workforce, hence a 
national project to develop a career framework for public health as a whole (Skills for Health and Public Health Resource Unit, 2006).

\section{Standards of professional conduct}

As the register grew in public profile and in size in the new millennium, the Society started to receive complaints about individual registrants. There was thus a need to offer more guidance on professional conduct than that in the brief code of ethics introduced at the inception of the Society's register (Nutrition Society, 1997), so that registrants and the public knew what to expect. The first statement of professional conduct was published as a separate document in 2003 (Nutrition Society, 2003b). The revised version (Nutrition Society, 2005b) includes the same code of ethics as that given earlier. These publications signal very clearly that oversight of professional standards protects the public, the hallmark of all modern professions, as well as protecting and promoting professional standards.

The register did not envisage that nutritionists would offer services to individual clients. However, professional boundaries have shifted because although public health is about work at the population level, all communities or groups comprise individuals. Thus, registered nutritionists may deal with individuals, drawn from communities and groups. In response to requests for guidance from registrants, and to protect the public, it is expected that registrants understand and work within the limits of their own competency, as set out in the statement of professional conduct (Nutrition Society, 2005b) that registrants formally affirm that they will abide by and be held to account.

Professional standards may be summarised as meaning 'fitness for practice', which is based on 'fitness for award' (academic standards) but also addresses employability that can be summarised as 'fitness for purpose'. In the latter aspect, fitness for practice is expected to indicate eligibility for entry into a professional occupation, thereby signifying eligibility for a professional job rather than a paraprofessional or support level job. This 'fitness' nexus is at the heart of modern professions in the UK. The Society at present expects a two-stage professional development process. The first is marked by acquisition of professional qualifications, and therefore is dominated by cognition ('knowing' and 'knowing how'). This stage underpins a second usually separate phase, expected to last 3 years, devoted to the development of professional competency. Only then is an associate registrant expected to be ready to show retrospectively that they have acquired professional competency consistent with full registration as an autonomous professional. The Society's approach to professional development most closely follows the path to a research career, in which an initial degree is followed by 3 years of supervised training and leading to a $\mathrm{PhD}$, which is a prerequisite for a career in academia and in research.

\section{Concepts of competency: proficiency}

The Society was prescient in adopting a competency approach to public health nutrition (Landman et al. 1998), but laid more emphasis on cognitive competencies than on the skills of application within the context of an occupational role. While professional registration in nutrition was a private matter (a membership benefit), not about public protection, the assumptions on which the Society's models of professionalisation were based were not open to test or scrutiny. However, now that the Society is set upon statutory regulation, professionalisation in nutrition becomes an explicitly public concern, and must meet the test of public protection above all others. So, it is essential to compare the Society's current approaches in nutrition with those in other modern professions. The Society's approach differs from the contemporary model of professional development in regulated health professions, in which there is integration between theory and practice, with formal professional training closely allied to education in 'underpinning knowledge'. For example, there is 'early patient contact' for medical students. The 1-year sandwich placements in dietetics have been replaced by three 'blocks' at varying points in the 3-4-year first-degree course. Nutrition also lags behind the 21 st century consensus that professions focus on patient or client benefit and that where possible and appropriate there should be interprofessional collaboration facilitated by interprofessional learning. Thus, there is an emerging common framework for the allied health professions with nursing and midwifery (Quality Assurance Agency, 2001, 2002). The allied health professions share common standards of proficiency (Health Professions Council, 2003a), standards of education and training (Health Professions Council, 2004) and standards of conduct, performance and ethics (Health Professions Council, 2003b). The Society needs to develop standards of proficiency that would be suitable for practice in the 'wider public health' (i.e. work in local and national government, private and voluntary sectors) at the threshold or professional entry level. In February 2006 the Society established a Modern Profession Taskforce under the chairmanship of the Honorary Secretary, Professor Catherine Geissler, to take forward this work and answer the question 'for what occupation is a professional registered nutritionist equipped'. The Society collated and analysed a convenience sample of fifty-eight job descriptions (all but one contemporary) that were supplied by members or advertised on the World Wide Web to fill vacancies. There were no jobs for animal nutritionists and the majority were in the health service. Thus, it has become possible for the first time to identify what standards of proficiency (i.e. performance) in nutrition are consistent with functioning as a professional registrant (Nutrition Society, 2006b). This Taskforce identified a gap that it recommended should be filled so that registered nutritionists are explicitly equipped to teach the core curriculum in nutrition (Department of Health, 1994) to other health professionals. These draft standards of proficiency were the subject of a consultation between July and September 2006. Further testing with practitioners will develop robust standards in Spring 2007.

The next step will be to develop guidance for prospective practical professional development, equivalent to standards of training in the health professions. For flexibility and affordability there may be practical experiences, through employment, formal training in placements or 
attachments, or through a mixture of all or some of these experiences. Either way, there will be assessment of competency, e.g. by means of portfolios of evidence or an objective structured nutrition professional examination, selected to be valid, credible and affordable.

\section{Re-registration based on evidence of continuing professional development}

A scheme for continuing professional development formally began in July 2006, signalling the start of a pilot year for the preparation of evidence of professional development before an audit starts in 2007. All registrants are expected to engage in continuing professional development. What is new is an obligation to collect evidence so that they can show how they have improved their professional practice in order to seek re-registration at fiveyearly intervals. The audit scheme will be piloted with Registered Public Health Nutritionists who were admitted before 2001. The Society's continuing professional development and re-registration scheme will work if it helps nutritionists to meet their own needs, the expectations of employers whether public sector or private sector.

The Food Standards Agency has supported a pilot to enable several volunteer professional nutrition staff to test how well the Society's scheme dovetails with their employer's individual performance review scheme. Thus, the Society will be able to show that its register meets public's expectations that regulated professionals are obliged to keep up to date (Department of Health, 2006a).

\section{Challenges in further professionalisation}

It has long been recognised that self-regulated professions hold influential positions, through their technical expertise delivered to government within the corridors of power wielded rationally based on scientific evidence and for the greater public good. In the 21st century the purveyors of expertise have lost their unique access to power and influence. The public's main means to engage with technocrats is through the politicians whom they elect and who they expect to function according to the so-called Nolan rules for the conduct of public life, in the public and charitable sectors (for example, see Department of Health, 2006a; Health Professions Council, nd). Politicians increasingly demand that public investments lead to measurable outputs and outcomes that improve the public good. Modern politics has accommodated powerful countervailing forces, as is evident from increasing transparency that is manifest in the proceedings of the Food Standards Agency and the Scientific Advisory Committee on Nutrition. In this climate it is politically difficult for governments to provide support for a membership organisation because of the risk of being perceived to have bowed to vested interests. Governments and the public expect modern professions to be models of good governance. Thus, the oversight of the Society's register now proceeds according to clear, transparent, fair, therefore consistent, rigorous standards, properly accountable to the Trustees in Council who govern all the affairs of the
Table 3. The Health Professions Council's set of tests that aspirant professions must pass for statutory registration to be considered necessary (Department of Health, 2006a)

Discrete area of activity

Defined body of knowledge

Evidence-based practice

One professional body representing most practitioners

Voluntary register

Defined entry routes to training

Independently-assessed qualifications

Code of conduct applied to voluntary registrants

Disciplinary processes applied to voluntary registrants

Commitment to continuing professional development

Table 4. Use of specific professional titles, 2005: the principal responses from nutritionists ( $n$ 920) when asked how they would describe their roles without mentioning their job titles in a survey carried out by Stockley and Associates, independent consultants (Nutrition Society, 2006a)

\begin{tabular}{lr}
\hline Nutritionist & 172 \\
Public health nutritionist & 35 \\
Nutritional therapist & 10 \\
Community nutritionist & 9 \\
Nutrition consultant & 7 \\
Clinical nutritionist & 6 \\
Nutritional biochemist & 5 \\
Nutritional scientist & 5 \\
Consultant nutritionist & 3 \\
Nutrition adviser & 3 \\
Associate or Registered Nutritionist & 4 \\
$\quad$ or Registered Public Health Nutritionist & \\
Nutritionist in combination with another term & 262
\end{tabular}

Society. This process required codification within the Society's constitution (Nutrition Society, 2003c), with supplementary standard operating procedures for registration (Nutrition Society, 2005b) and for course accreditation (Nutrition Society, 2006c). Steps have been taken to meet an explicit goal of increasing lay membership of the Society's committees. In due course there will be independent chairmanships, so that the public interest is seen to be represented.

Registered nutritionists lay easy claim to a knowledge base for their profession, because of the success of the Society's journals and introductory and advanced texts, which refresh the discipline that underpins most if not all the practice of nutrition. However, there is another argument to be waged and won, i.e. to show how the nutrition sciences directly inform practice or practice development; how does nutritional professional activity improve in line with evidence? This question is one that all modern professions have to answer clearly and explicitly. It is evident that it is easier to make a case for a homogenous profession with clearly-defined procedures for which there are routines written into protocols than it is for diversity of jobs or activities. There is also a need to be able to explain the nutrition profession to several audiences of nonnutritionists and to other nutrition professionals who should provide the formal support required before the 
Health Professions Council agrees to recommend a change in the law, based on their requirements, as shown in Table 3. The audiences also include lay individuals, the recipients of the nutritionist's services or their clientele, ultimately the electorate who elect the politicans, and of course the politicians who will need to be persuaded to change the law to regulate nutrition as a profession. In 2005 Stockley and Associates, independent consultants, found that an overwhelming majority of respondents (98\%) supported statutory regulation for nutritionists (Nutrition Society, 2006a) and found support from other nutrition and health professionals in this and their previous study (Nutrition Society, 2004). Changing the law requires that the Society persuades others. To achieve this objective requires that the nutritionists are very clear about their own professional identity, role, culture and values.

Professional identity is perhaps the critical challenge, because few nutritionists describe themselves in terms of their professional titles, Registered Nutritionist, Registered Public Health Nutritionist (Nutrition Society, 2006a), as was also found by Ashwell (1993). Instead, there was a wide diversity of titles that seemed to reflect a desire to express respondents' uniqueness and individuality, not membership of the collectivity that is a profession (Table 2 and Table 4)

This situation makes protection of title impossible. Nutritionists need to turn their shared value of improving public nutrition into a desire to provide practical services that benefit the public health and/or wealth. They need to forge an explicit strong sense of collective professional identity. At a time of change it is timely to forge that professional identity together.

\section{References}

Ashwell M (1993) Nutritionists! Stand up and be counted. Nutrition Bulletin 18, 164-171.

Ashwell M \& Cole TJ (1986) The Nutrition Society in the 1980s: The questionnaire analysis. Proceedings of the Nutrition Society 45, 231-252.

Department of Health (1994) Core Curriculum for Nutrition in the Education of Health Professionals. London: Department of Health.

Department of Health (2000) The NHS Plan: A Plan for Investment, A Plan for Reform. London: Department of Health.

Department of Health (2001) The Report of the Chief Medical Officer's Project to Strengthen the Public Health Function. London: Department of Health.

Department of Health (2004a) Choosing health: making healthy choices easier. http://www.dh.gov.uk/assetRoot/04/12/07/92/ 04120792.pdf

Department of Health (2004b) The NHS Knowledge and Skills Framework (NHS KSF) and the Development Review Process (October 2004). London: Department of Health.

Department of Health (2005a) Choosing a better diet: a food and health action plan. http://www.dh.gov.uk/assetRoot/04/10/57/ 09/04105709.pdf

Department of Health (2005b) Choosing activity: a physical activity action plan. http://www.dh.gov.uk/assetRoot/04/10/57/ 10/04105710.pdf

Department of Health (2005c) Delivering choosing health: making healthier choices easier. http://www.dh.gov.uk/assetRoot/ 04/10/57/13/04105713.pdf
Department of Health (2005d) Choosing Health: Investing in the Workforce. London: Department of Health.

Department of Health (2005e) Agenda for change. http://www. dh.gov.uk/PolicyAndGuidance/HumanResourcesAndTraining/ ModernisingPay/AgendaForChange/fs/en

Department of Health (2006a) The regulation of non-medical healthcare professions: a review by the Department of Health. http://www.dh.gov.uk/assetRoot/04/13/72/95/04137295.pdf

Department of Health (2006b) Good doctors safer patients. Proposals to strengthen the system to assure and improve the performance of doctors and to protect the safety of patients. http://www.dh.gov.uk/assetRoot/04/13/72/76/0413276.pdf

Food Standards Agency, Wales (2004) Food and well being. Reducing inequalities through a nutrition strategy for Wales. http://www.food.gov.uk/multimedia/pdfs/foodandwellbeing.pdf

Health Development Agency (2001) Coronary Heart Disease. Guidance for Implementing the Preventive Aspects of the National Service Framework, pp. 26-27. London: Health Development Agency; available at http://www.nice.org.uk/ download.aspx?;o=501951

Health Professions Council (2003a) Standards of proficiency dietitians. http://www.hpc-uk.org/assets/documents/1000050C Standards_of_Proficiency_Dietitians.pdf

Health Professions Council (2003b) Standards of conduct, performance and ethics. http://www.hpc-uk.org/assets/documents/ 1000062CHPC034HPCA5_Standards_of_conduct_performance_ and_ethics.pdf

Health Professions Council (2004) Standards of education \& training. http://www.hpc-uk.org/assets/documents/10000BC F46345Educ-Train-SOPA5_v2.pdf

Institute of Biology (1991) Training of Nutritionists. A Report for the Nutrition Society by the Institute of Biology's Review Group on the Training of Nutritionists. London: Institute of Biology.

Institute of Biology (1995) Register of Accredited Nutritionists sponsored by the Institute of Biology, the Nutrition Society, and the Institute of Food Science and Technology, 3rd ed. London: Institute of Biology.

Landman J, Buttriss J \& Margetts B (1998) Curriculum design for professional development in public health nutrition in Britain. Public Heath Nutrition 1, 69-74.

Landman J, Wootton SA \& Jackson AA (2006) The nutrition workforce for achieving public health; competency, training, and capacity development. http://www.sacn.gov.uk/pdfs/sacn_ 06_36.pdf

Nutrition Society (1997) Register in Public Health Nutrition: Philosophy and How to Apply. London: Nutrition Society.

Nutrition Society (2003a) Guidelines for accrediting university courses in nutrition. Report of the Nutrition Science and Association of Professors in Human Nutrition Working Party on Nutrition Science. http://www.nutritionsociety.org/ documents/20050816courseaccred.pdf

Nutrition Society (2003b) Nutrition Society Professional Conduct. London: Nutrition Society.

Nutrition Society (2003c) The Nutrition Society Rules. London: Nutrition Society.

Nutrition Society (2003d) Nutrition Society's Registration Committee (NSRC) constitution, regulations and revised standard operating procedures. http://www.nutritionsociety.org/ documents/20060411NutSocSOPS.pdf

Nutrition Society (2004) Understanding the difference between nutrition health professionals. http://www.nutritionsociety.org/ documents/20060629fulldefiningnutritionreportforcouncil.pdf

Nutrition Society (2005a) Course accreditation for nutrition courses. Guide to application. http://www.nutritionsociety. org/documents/20060411NotesforNutritionCourseApplication. pdf 
Nutrition Society (2005b) Professional registration in nutrition. Code of ethics and statement of professional conduct. http://www.nutritionsociety.org/documents/18022005/New\% 20code $\% 20$ of $\% 20$ conduct.pdf

Nutrition Society (2006a) Nutrition capacity in the United Kingdom: mapping the 'primary' nutrition workforce. Full report. http://www.nutritionsociety.org/documents/20060629 NutritionCapacityFullReport.pdf

Nutrition Society (2006b) The modern profession. Draft standards of proficiency. Public written consultation, July 2006. http://www.nutritionsociety.org/documents/20060718Draft StandardsOfProficiency.pdf.

Nutrition Society (2006c) Nutrition Society's Course Accreditation Committee (CAC) Constitution, Regulations and Standard Operating Procedures. London. Nutrition Society.

Nutrition Society (2006d) Strategic plan 2007-2010. http:// www.nutritionsociety.org/documents/20060609Stratplan.pdf

O'Hara-May J (1987) Nutritionists' views on nutrition. Proceedings of the Nutrition Society 41, 265-284.

Quality Assurance Agency (2001) Benchmark statement: Dietetics. http://www.qaa.ac.uk/academicinfrastructure/benchmark/ health/Dietetics.pdf
Quality Assurance Agency (2002) Benchmark statement: health care programmes. http://www.qaa.ac.uk/academicinfrastructure/ benchmark/health/physio.pdf

Scottish Executive (2004) Eating for health: meeting the challenge. http://www.scotland.gov.uk/Resource/Doc/47060/ 0012960.pdf

Skills for Health and Public Health Resource Unit (2006) Public Health Career Framework. http://www.publichealthdevelopment. org.uk/PH\%20career\%20framework\%20Dec06.pdf

The British Dietetic Association and The Nutrition Society (2002) Joint professional development guidance on the employment of nutritionists in NHS nutrition and dietetic departments. https://www.nutritionsociety.org/documents/ 20060412NutritionistsinNHS.pdf

Wanless D (2004) Securing good health for the whole population. Final report to HM Treasury. http://www.hm-treasury.gov.uk/ consultations_and_legislation/wanless/consult_wanless04_ final.cfm

Waterlow JC (1981) Crisis for nutrition. Proceedings of the Nutrition Society 40, 195-207.

Waterlow JC (1984) Our Society in the 1980s. Proceedings of the Nutrition Society 43, 315-318. 